\title{
Evaluation of Arctic broadband surface radiation measurements
}

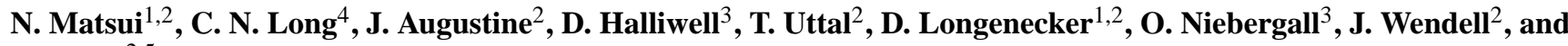 \\ R. Albee 2,5 $^{2,5}$ \\ ${ }^{1}$ Cooperative Institute for Research in Environmental Sciences, Boulder, Colorado, USA \\ ${ }^{2}$ National Oceanic and Atmospheric Administration, Boulder, Colorado, USA \\ ${ }^{3}$ Environment Canada, Regina, Saskatchewan, Canada \\ ${ }^{4}$ Pacific Northwest Laboratory, Richland, Washington, USA \\ ${ }^{5}$ Scientific Technology Corporation, Boulder, Colorado, USA
}

Correspondence to: N. Matsui (nobuki.matsui@colorado.edu)

Received: 17 June 2011 - Published in Atmos. Meas. Tech. Discuss.: 2 August 2011

Revised: 30 January 2012 - Accepted: 14 February 2012 - Published: 24 February 2012

\begin{abstract}
The Arctic is a challenging environment for making in-situ surface radiation measurements. A standard suite of radiation sensors is typically designed to measure incoming and outgoing shortwave (SW) and thermal infrared, or longwave (LW), radiation. Enhancements may include various sensors for measuring irradiance in narrower bandwidths. Many solar radiation/thermal infrared flux sensors utilize protective glass domes and some are mounted on complex mechanical platforms (solar trackers) that keep sensors and shading devices trained on the sun along its diurnal path. High quality measurements require striking a balance between locating stations in a pristine undisturbed setting free of artificial blockage (such as from buildings and towers) and providing accessibility to allow operators to clean and maintain the instruments. Three significant sources of erroneous data in the Arctic include solar tracker malfunctions, rime/frost/snow deposition on the protective glass domes of the radiometers and operational problems due to limited operator access in extreme weather conditions. In this study, comparisons are made between the global and component sum (direct [vertical component] + diffuse) SW measurements. The difference between these two quantities (that theoretically should be zero) is used to illustrate the magnitude and seasonality of arctic radiation flux measurement problems. The problem of rime/frost/snow deposition is investigated in more detail for one case study utilizing both SW and LW measurements. Solutions to these operational problems that utilize measurement redundancy, more sophisticated heating and ventilation strategies and a more systematic program of operational support and subsequent data quality protocols are proposed.
\end{abstract}

\section{Introduction}

The radiative balance of the earth-atmosphere system is crucial for understanding atmospheric processes (Dines, 1917; Hunt et al., 1986; Kiehl and Trenberth, 1997; Le Treut et al., 2007; Trenberth et al., 2009) because it plays a pivotal role in determining atmospheric circulations (Ohmura et al., 1998). The surface radiation budget is especially pertinent to weather and climate, as the earth surface transforms about $60 \%$ of solar radiation absorbed by the planet to heat (Ohmura et al, 1998). The Arctic has already shown its enhanced sensitivity to anthropogenic gas induced climate changes (IPCC AR4, 2007), but because the actual mechanisms that produce climate change are surface processes, which are greatly affected by poorly understood Arctic clouds (see Solomon et al., 2008 for their concise and extensive historical account on Arctic cloud research), more extensive research on the arctic surface radiation budget (e.g., Dutton et al.,2006; Dong et al., 2010) and an extensive network of surface radiation measurements are needed. For example, Kay et al. (2008) showed that enhanced surface radiation due to the decreased cloud cover by $16 \%$ from 2006 to 2007 alone could enhance surface melt by $0.3 \mathrm{~m}$ over the Western Arctic ocean. Sea-ice extent, permafrost active layer temperatures, seasonal snow cover and depth, glacier advance/retreat rates and vegetation also influence arctic surface processes. Given that, (1) Arctic clouds and their effects on radiative transfer and the surface radiation budget are poorly represented in models (Curry, 2000; Solomon et al., 2008), and (2) that satellite remote sensing algorithms cannot accurately retrieve arctic surface and cloud characteristics 
Table 1. Arctic stations with radiation instruments.

\begin{tabular}{llllll}
\hline Station & Location & Height & Operating since & Operator & BSRN archived \\
\hline Alert & $82^{\circ} 86^{\prime} 67^{\prime \prime} \mathrm{N}$, & $210 \mathrm{~m}$ & Aug 2004 & EC & Candidate \\
& $64^{\circ} 58^{\prime} 33^{\prime \prime} \mathrm{W}$ & & & & \\
Barrow & $71^{\circ} 19^{\prime} \mathrm{N}$, & $8 \mathrm{~m}$ & 1976 & GMD/NOAA & Yes \\
& $156^{\circ} 36^{\prime} \mathrm{W}$ & & & & \\
Eureka & $79^{\circ} 59^{\prime} 47.50^{\prime \prime} \mathrm{N}$, & $10 \mathrm{~m}$ & 2007 & EC & Candidate \\
& $85^{\circ} 48^{\prime} 15.80^{\prime \prime} \mathrm{W}$ & & & & \\
Ny-Alesund & $78^{\circ} 56^{\prime} \mathrm{N}$, & $11 \mathrm{~m}$ & 1988 & AWI & Yes \\
& $11^{\circ} 57^{\prime} \mathrm{E}$ & & & & \\
Summit & $72^{\circ} 56^{\prime} 67^{\prime \prime} \mathrm{N}$, & $3238 \mathrm{~m}$ & 2000 & NSF & Candidate \\
& $38^{\circ} 48^{\prime} 33^{\prime \prime} \mathrm{W}$ & & & & \\
Tiksi & $35^{\circ} 48^{\prime} \mathrm{N}$, & $32 \mathrm{~m}$ & 2010 & GMD/NOAA & Candidate \\
& $128^{\circ} 53^{\prime} \mathrm{W}$ & & & & \\
\hline
\end{tabular}

(Randall et al., 1997), high-quality arctic surface radiation measurements are essential to the eventual understanding of these problems. In recognition of the importance of these measurements, a number of arctic observatories have installed suites of broadband irradiance (radiation flux) sensors (hereafter radiation sensors) for measuring the components of incoming and outgoing shortwave (SW) and longwave $(\mathrm{LW})$ radiation.

Radiation measurements at high latitudes have many difficulties associated with extreme weather conditions such as rime deposition and snow accumulation on the protective domes of the instruments, solar tracker failures, and calibration temperature compensation (Lanconelli et al., 2011). In this paper, we report on unique challenges we have experienced in making surface radiation measurements at Barrow, Alaska and in Canada at Alert and Eureka. The suites of radiation sensors deployed at these stations are generally compliant with the standards of the Baseline Surface Radiation Network (BSRN) (McArthur, 2004). The BSRN is a cooperative worldwide network that provides continuous, researchquality surface radiation flux measurements. One of its key missions is to validate GCMs (e.g. Wild et al., 2001) and satellite retrievals of surface radiative processes (e.g. Zhou et al., 2007).

No scientific measurements, especially in the harsh arctic environment, are complete without the application of data quality control (QC) procedures to flag erroneous data. The BSRN recognizes the need for establishing data QC procedures using existing methods (informal report, ELEVENTH Baseline Surface Radiation Network, BSRN, Scientific Review and Workshop, Queenstown, New Zealand, 13-16 April 2010). Currently not all the BSRNrecommended quality control procedures are made centrally at the World Radiation Monitoring Center (Lanconelli et al., 2011). However, according to the BSRN, it is primarily the responsibility of the site scientist to supply the best data possible to the archive. In response to that requirement we are in the process of implementing quality control procedures embodied by "QCRad," which were developed by Long and Shi (2006), on the radiation measurements at Eureka (Matsui et al., 2010). The QCRad program is based on BSRN recommendations for data QC, but with significant improvements (Long and Shi, 2008). It consists of 19 tests that utilize auxiliary data such as case and dome temperatures of the pyrgeometers, station pressure, temperature, and relative humidity to gauge radiation measurements against both physical and climatological limits.

\section{State of radiation data in the Arctic}

Current arctic surface irradiance measurements are lacking and insufficient. Barrow and Ny-Alesund are the only stations with decadal radiation records, starting 1976 and 1988 respectively (Table 1). Given the accumulation of decadal radiation records at a few sites and the addition of new arctic stations, we have finally begun to see climatological research on the arctic surface radiation budget (Dutton et al., 2006; Dong et al., 2010). This small step forward has prompted Sutter (2006) to call for homogenization (bias corrections over time) of arctic data and consistent calibration of radiation sensors for the four polar stations: Barrow, Ny-Alesund, Neumayer, and South Pole.

Currently, only six arctic stations have downward and upward radiation measurements. They are Alert (Nunavut, Canada), Barrow (Alaska), Eureka (Nunavut, Canada), NyAlesund (Norway), Summit (Greenland), and Tiksi (Russia) (Table 1). Ancillary instruments on the nearby towers supplement upward radiation measurements at Eureka and Tiksi. A list of operators for those stations is shown in Table 1. Of these, only Barrow and Ny-Alesund data have been archived by the BSRN. Figure 1 shows the polar projection map with 


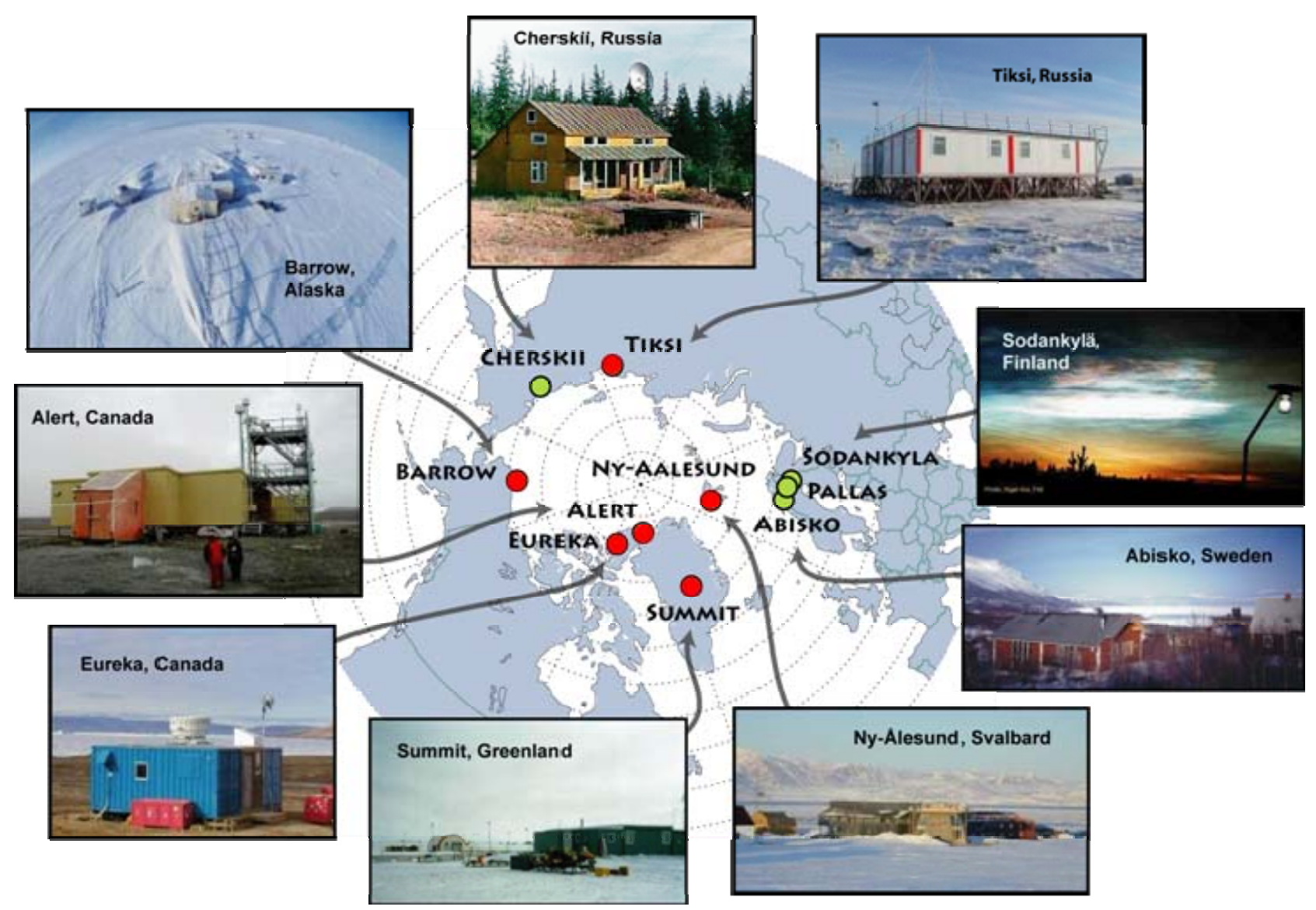

Fig. 1. Polar projection map with IASOA (International Arctic Systems for Observing the Atmosphere) stations (Darby et al., 2009). Red circles mark those stations with radiation instruments.

IASOA (International Arctic Systems for Observing the Atmosphere) stations (Darby et al., 2009), which is a network of value added arctic observatories. Red circles indicate stations that have radiation sensors. Despite the recent addition of Tiksi, there remains a large geosampling gap in Russia. However, there have been various short-term ancillary radiation measurements in Russia such as those of the GEWEX Asian Monsoon Experiments (Yasunari, 2001). There also exists a network of Russian radiation sensors and the calibration of those instruments against BSRN standard compliant instruments is underway in Tiksi (Uttal et al., 2010).

Likewise, less technically challenging but more established atmospheric state measurements in the Arctic also do not extend as far back as those at lower latitudes. Among the eight IASOA stations, Tiksi has the longest temperature and surface pressure record, dating back to 1933. In contrast, the global dataset of atmospheric state variables begins well before 20th century. For example, the Global Historical Climatology Network version 2 temperature database begins in 1850 (Peterson and Vose, 1997), and the International Surface Pressure Databank version 2.2 starts in 1768 (Yin et al., 2008).

\section{Radiation measurements and the surface energy budget}

The BSRN recommends that the primary measurement of total solar downwelling irradiance should be the sum of the diffuse and direct horizontal components. Therefore, compliant measurements require a solar tracker (Fig. 2). Trackermounted instruments include a shaded pyranometer to measure diffuse SW irradiance on a horizontal surface, and a pyrheliometer to measure direct SW irradiance normal to the sun's beam. The BSRN also recommends a shaded pyrgeometer to measure downwelling LW thermal infrared irradiance on a horizontal surface (Ohmura et al., 1998; McArthur, 2004). Shading the up-pointing pyrgeometer helps mitigate solar contamination of the downwelling atmospheric thermal LW measurement and errors associated with uneven dome heating. Shade disks mounted on the tracker enable the shaded measurements by blocking the direct sun. Upwelling global SW and LW irradiance measurements can be made from a short tower preferably poleward of the tracker and other measurement platforms to avoid shading of those radiometers, and in close proximity to the tracker location. For 


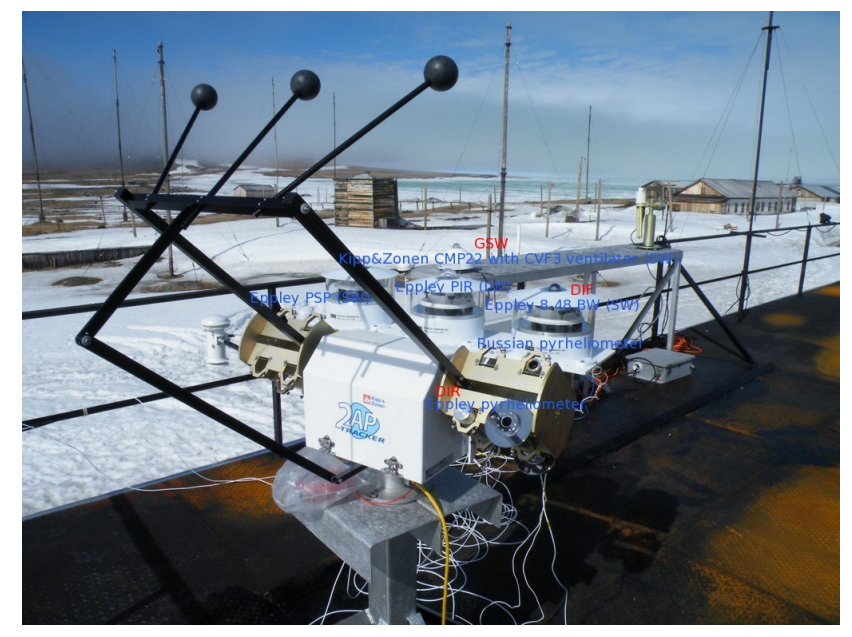

Fig. 2. Solar tracker mounted surface radiation sensors in Tiksi, Russia. Shortwave measurements are made by GSW (global shortwave), DIR (direct), and DIF (diffuse) sensors.

redundancy, an unshaded pyranometer that measures global SW may be placed on the shade platform of the solar tracker (but not shaded) or on a separate stand nearby. Many variants of BSRN radiation sensor suite implementations exist. For example, in Tiksi, Russia, two different types of shaded diffuse SW sensors are used, and the global SW sensor is situated nearby (Fig. 2).

Michalsky et al. (1999) have shown that in low sun and cold conditions the component sum methodology could lower the uncertainty by a factor of 2 or 3 , with respect to a single pyranometer global SW measurement. Upper panels of Fig. 3 show global horizontal irradiance plotted over the component sum for Alert, Barrow, Eureka and BAO (Boulder Atmospheric Observatory in Colorado) for 2008. For the purpose of illustration, the data shown are not quality controlled, and a 45-min running average is applied. Lower panels of Fig. 3 show the difference between the component sum and the measured global horizontal irradiance. Theoretically that difference should be zero. However due to harsh weather conditions and errors inherent to the global solar measurement by a single pyranometer, such as the cosine error of its sensor and thermal offset errors (Robinson, 1966; Gulbrandsen, 1978; Dutton et al., 2001; Philipona, 2002) which are particularly relevant to arctic locations under clear skies, perfect agreement is rarely achieved. These comparisons show that significant errors tend to occur preferentially in the early spring, especially in the arctic. Similar results were found for 2009 and 2010 but not shown. Of the arctic stations, Eureka shows the least disagreement. The purpose of showing the Colorado station in Fig. 3 is to illustrate the climatological differences between high- and mid-latitude stations, and also to show that arctic stations tend to have more measurement problems than those in less harsh environments.
Upwelling radiation and surface energy flux measurements are not required by the BSRN. The disadvantage of not having a full suite of radiation budget and surface energy flux measurements is illustrated by the following theoretical consideration.

Net surface irradiance is characterized by Eq. (1) where $\mathrm{LW}_{\text {net }}$ is the difference between its downwelling and upwelling LW components, and $\mathrm{SW}_{\text {net }}$ is the difference between downwelling and upwelling SW components.

$R_{\text {net }}=\mathrm{LW}_{\text {net }}+\mathrm{SW}_{\text {net }}=(\mathrm{LW} \downarrow-\mathrm{LW} \uparrow)+(\mathrm{SW} \downarrow-\mathrm{SW} \uparrow)$.

BSRN compliant stations may only satisfy Eq. (1) if they have ancillary upwelling radiation measurements. Additional measurements of latent $\left(Q_{\mathrm{E}}\right)$, sensible $\left(Q_{\mathrm{H}}\right)$, and ground conductive fluxes $\left(Q_{\mathrm{G}}\right)$ are necessary to fully characterize the surface energy budget. Energy conservation dictates that the difference between the surface net radiation and surface energy fluxes is the energy that would be available for residual melting $\left(Q_{\mathrm{M}}\right)$, but that difference would also include all measurement errors $(\varepsilon)$.

$R_{\text {net }}+\left(Q_{\mathrm{H}}+Q_{\mathrm{E}}+Q_{\mathrm{G}}\right)=Q_{\mathrm{M}}+\varepsilon$.

Without coincident surface net radiation and energy flux measurements, it is impossible to definitively determine how the net radiation at the surface is utilized, which is what models have to simulate correctly.

\section{The flux tower in Eureka}

Eureka is located on the Fosheim Peninsula of Ellesmere Island, Nunavut. There, NOAA monitoring instruments are collocated with a Canadian station called the Surface and Atmospheric Flux, Irradiance and Radiation Extension (SAFIRE) located at $79^{\circ} 59^{\prime} 47.50^{\prime \prime} \mathrm{N}, 85^{\circ} 48^{\prime} 15.80^{\prime \prime} \mathrm{W}$. The SAFIRE building rooftop is instrumented with Environment Canada tracker-mounted radiometers that measure downwelling SW and LW irradiance (Fig. 4, left panel). The NOAA $10.5 \mathrm{~m}$ flux tower (Fig. 4, right panel), erected in 2007, is located about $500 \mathrm{~m}$ east of the SAFIRE building at $79^{\circ} 59^{\prime} 43.4^{\prime \prime} \mathrm{N}, 85^{\circ} 46^{\prime} 22.9^{\prime \prime} \mathrm{W}$. The top of that tower is instrumented with both up- and down-pointing global horizontal pyranometers (Kipp and Zonen CM22) and pyrgeometers (Eppley PIR). Thus Eureka has two sets of global SW and LW sensors that measure downwelling irradiance, and one set that measures upwelling irradiance. Maintenance of the tower-mounted radiometers in the arctic winter is extremely difficult and dangerous. Manual inspections of downwelling SW measurements show frequent erroneous data primarily due to riming. Unfortunately, the placement of downwelling sensors on the top of the tower was a logistical mistake and likely resulted in more bad data than if they were placed near the surface where they could have been more easily serviced.

Figure 5 shows downwelling SW measurements from the Environment Canada solar tracker at Eureka and the 

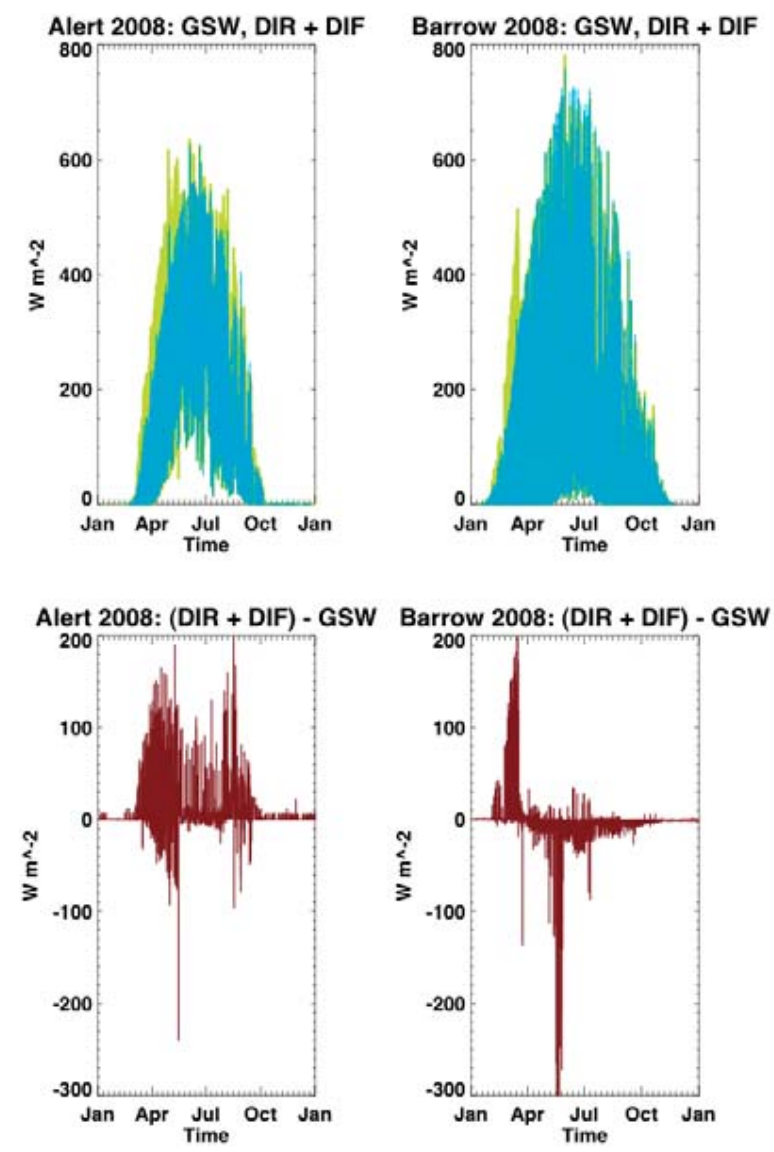
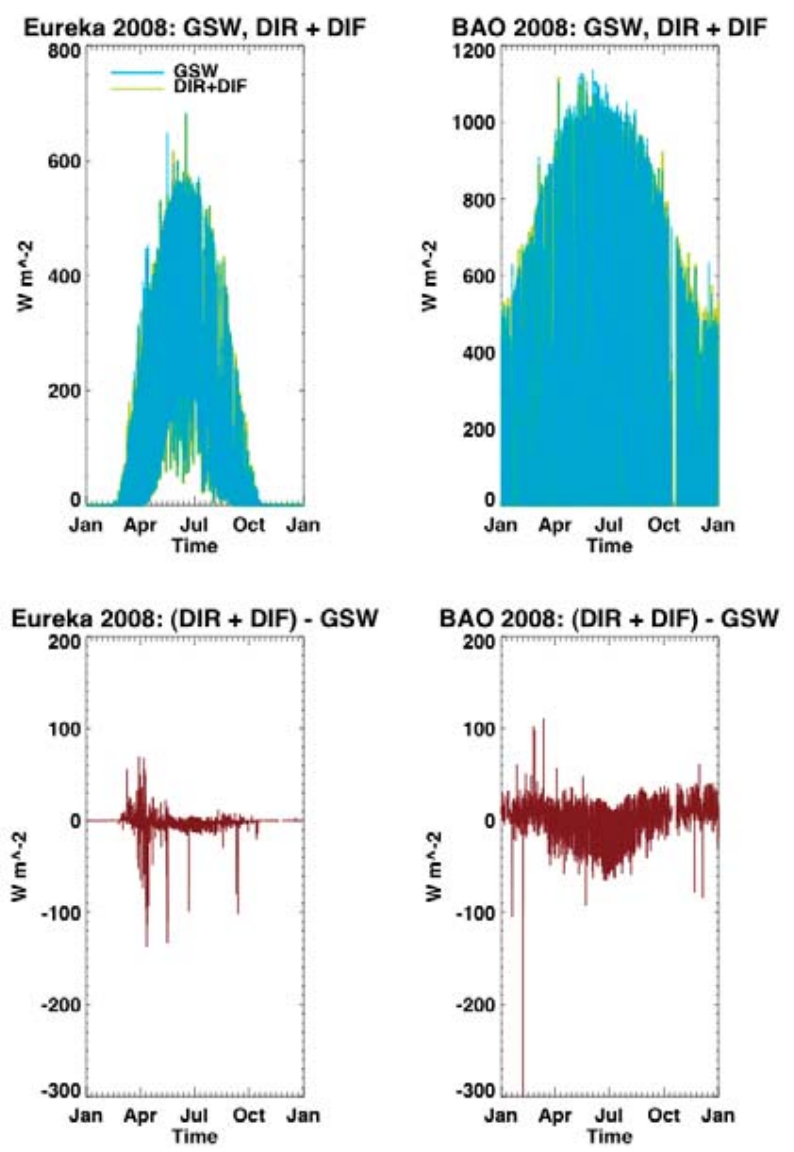

Fig. 3. GSW and DIF + DIR: Comparison of (a) Alert, (b) Barrow, (c) Eureka and (d) BAO (Boulder Atmospheric Laboratory) in 2008. The top panels show GSW and the component sum. The bottom panels show the difference between the component sum and GSW.

flux tower downwelling SW and LW measurements for 26 March 2010. The solar beam, depicted by the directnormal measurement corrected to a horizontal surface, appears to be blocked before 13:00 UTC, but after that time it dominates the diffuse $\mathrm{SW}$, and appears to follow a cosine response. This suggests strongly that we are looking at clear skies after 13:00 UTC on that day. The Environment Canada global measurement is greater than the component sum by about $40 \mathrm{Wm}^{2}$ prior to about 20:30 UTC, when, according to station records, their diffuse and global instrument domes were cleared of a light frost. This is not uncommon (especially for the global measurement) at low solar elevations. After the cleaning, the magnitudes of both the diffuse and global measurements decrease, and consequently the component sum and global measurements better agree to within about $15 \mathrm{Wm}^{-2}$. A frosted dome often acts as a reflector/diffuser that reduces the cosine losses and enhances the irradiance on the horizontal sensor. This effect is usually not as noticeable on a diffuse sensor that is shaded from the direct sun, but perhaps in this case the diffuse radiation field was non-isotropic. Because the Environment Canada diffuse and global SW measurements adjust downward after they are cleared of snow and the direct SW remains unchanged indicates that the direct irradiance was the only good measurement prior to 13:00 UTC.

The magnitude of the NOAA tower global measurement is much greater than all other solar measurements throughout the day, indicating that it was greatly compromised by frost on its dome that could not be cleaned off because of its location at the top of the tower. Further, the extraterrestrial SW irradiance at Eureka peaks at about $300 \mathrm{Wm}^{-2}$ on 26 March. Because the downwelling SW measurement from the tower on that day peaked at $350 \mathrm{Wm}^{-2}$, and it is known that the day was cloud free after 13:00 UTC, it is safe to conclude that riming compromised the measurement of downwelling global SW irradiance on the tower.

Prior to 13:00 UTC, the downwelling solar measurements, including the direct beam, are quite a bit less than the clearsky values afterwards. The downwelling IR time series shows enhanced values prior to 13:00 UTC that favor the existence of overhead cloud cover during that period, suggesting clouds as the likely cause of the early morning reduction of downwelling SW. 


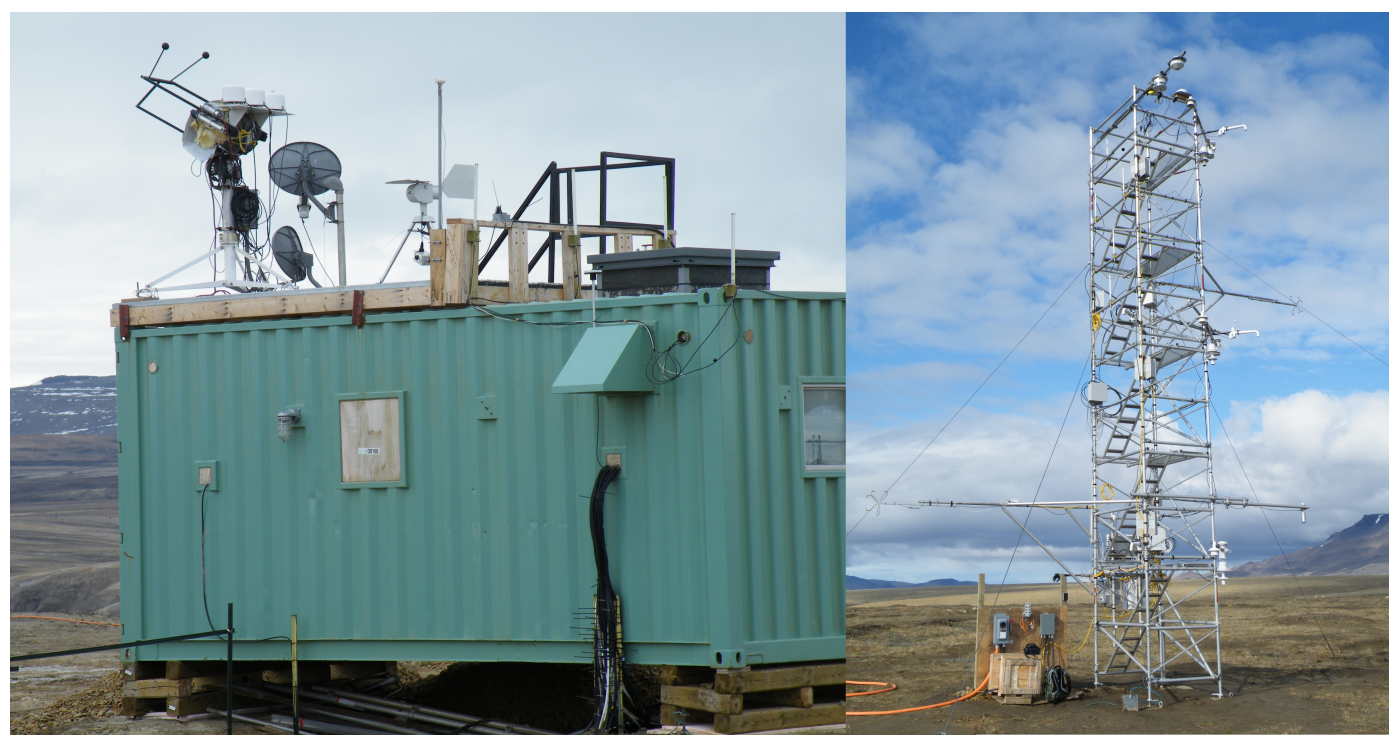

Fig. 4. SAFIRE rooftop is instrumented with tracker-mounted radiometers (left panel). At $10.5 \mathrm{~m}$ height, the flux tower is equipped with four radiometers (right panel).
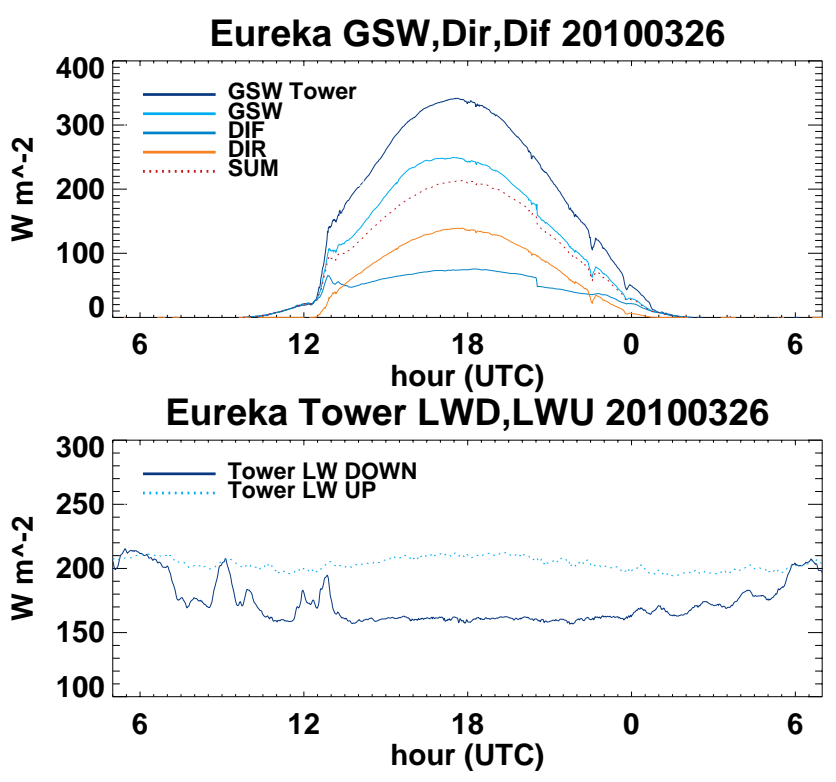

Fig. 5. Comparison between flux tower measurements of LWup, LWdown and global SW with SW DIF, DIR and their sum from SAFIRE measurements at Eureka on a mostly clear day, 26 March 2010.

\section{Discussion}

There are several strategies and practices regarding Arctic instrumentation that could lead to improved measurements. For example, there have been various creative solutions (many unpublished) invented by the well-experienced field workers in polar region such as extensive ventilator modifications during the SHEBA campaign (Horst, 2003).
Our suggestions here are not meant to be complete. It would be to our delight if these suggestions would invigorate further discussions among field operators and researchers that would lead to optimal local instrumentation strategies and better quality data.

\subsection{Common sense strategy}

Measurement improvement can be achieved by common sense strategies such as daily or sub-daily cleaning of the instruments. Ideally the instruments should be checked on an hourly basis, as practiced at many meteorological stations, but where that regimen is impractical, they should be examined daily, or on a subdaily basis if conditions favor riming. Remote stations should be checked at least weekly. If riming issues are persistent, it should be noted in the log entries. This is exactly the procedure Environment Canada SAFIRE station operators followed on 26 March 2010.

\subsection{Station design}

Well-designed instrument placement is the key to success for accurate arctic irradiance measurements. Figures 3 and 5 show the benefit of well-attended measurements. The fact that the solar tracker is located on the rooftop of the SAFIRE building where operators reside and have easy access is an asset that should be considered in the design of Arctic radiation measurement stations. Radiometers that measure downwelling irradiance should never be placed where they are not easily accessible. If at all possible, ancillary downpointing radiometers on the flux towers such as one in Eureka may supplement the tracker-mounted downwelling measurements to close the surface radiation budget, if (1) they are in 


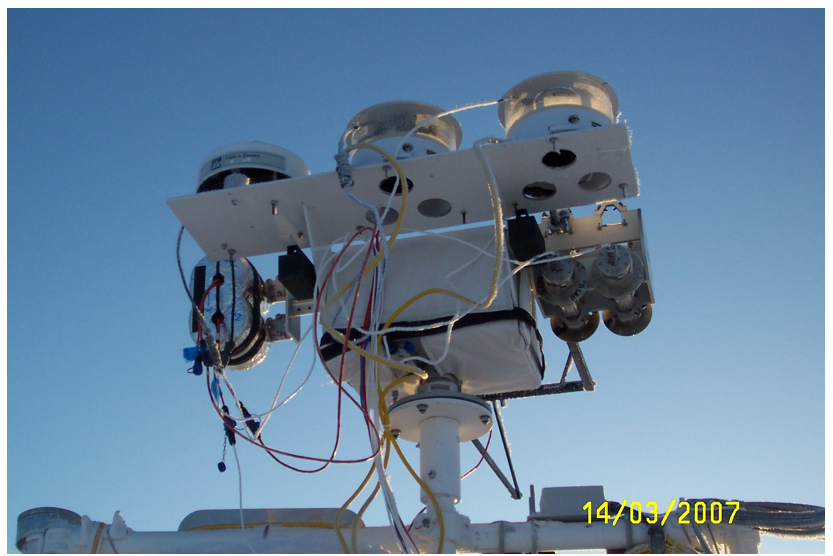

Fig. 6. Example solar tracker and its circuit box wrapped in the arctic-rated blanket.

reasonable proximity, and (2) the surface characteristics beneath the tower are representative of the surrounding area. The same argument applies to surface heat flux measurements that, in combination with the surface radiation budget, would close the surface energy budget measurements at a station.

\subsection{Instrument improvements}

Erroneous data due to the tracker operation issues, power failures, and riming on the instrument domes are primary concerns for arctic radiation measurements. During the long polar winter, when the sun is below the horizon all day, site operators program the modern robotic solar trackers to a lower latitude where the solar beam is still trackable to keep the tracker moving and thus maintain the fluidity of the grease and moving parts (J. Wendell and R. Albee, personal communication, 2010). The active sun tracking option is turned off during this period. The tracker is re-programmed to the correct coordinates a few weeks before the polar sunrise. Whether this procedure is necessary is a matter of debate. Solar trackers in arctic are usually equipped with an Arctic rated blanket to help retain the internally generated heat (Fig. 6). At NOAA/Global Monitoring Division an experiment was conducted in the cold chamber to test the effectiveness of the blanket and a simulated power failure. A solar tracker was brought to the state of cold soak by being powered off while the chamber temperature was dropped to $-70^{\circ} \mathrm{C}$. After the power was restored, the tracker circuit box temperature was brought back to operational temperature by the internal heater and the motors and mechanical gears were deemed operational (J. Wendell and R. Albee, personal communication, 2010). However, we are not certain that the chamber environment sufficiently simulated actual conditions of the early arctic spring. Tracker operation immediately before and during the polar sunrise requires further scrutiny.

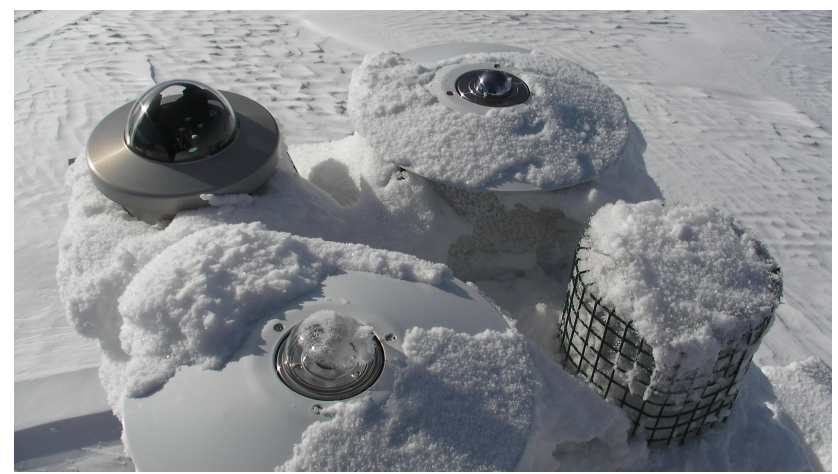

Fig. 7. SPN-1 radiometer (upper left), ventilated Eppley PSP radiometer (lower left) and ventilated Eppley PIR pyrgeometer (upper right). A thin layer of frost on the PSP's dome is clearly visible.

Having collocated redundant sensors could remedy some of the issues we have encountered in the Arctic. An example of such an arrangement is shown in Fig. 7. The top left corner of Fig. 7 shows the Delta-T Devices model SPN-1 radiometer (Myers, 2010) after a riming event at the Storm Peak Lab near Steamboat Springs, Colorado. With no moving parts, the SPN-1 radiometer utilizes seven small thermopile sensors with various degrees of shading to provide total and diffuse broadband SW measurements regardless of azimuthal orientation, from which direct SW is inferred. It has a built-in heating system that works down to $-20^{\circ} \mathrm{C}$ (in still air conditions) from Delta-T product sheet to keep dew, frost, rime, and snow off of the dome. The effectiveness of the internal heating system is obvious in the picture. The SPN-1 is not as accurate as a class-1 pyranometer, or component sum measurements, however, the benefit of such redundant measurements is obvious when the tracker or the trackermounted sensors are not functioning optimally (e.g., due to frost or tracker misalignment). For example, pyrheliometers typically are not equipped with ventilators and thus are more susceptible to riming. During the ARM StormVEx campaign (Mace et al., 2010) at Storm Peak Lab, the measurement system included an SPN-1 and an Eppley PSP (Fig. 7). Figure 8 shows the comparison of those two radiometers' measurements for 25 November 2010. That day was mostly clear, as confirmed by a Total Sky Imager (TSI) movie. The maximum solar elevation was just above $28^{\circ}$. The magnitude of the erroneously enhanced positive downwelling SW irradiance that was experienced at the Eureka flux tower due to riming was replicated in the Eppley PSP morning data on this date. Since the sky was mostly clear, the afternoon total SW irradiance should nearly match the curve in the morning, only showing small differences due to diurnal changes in water vapor and aerosol loading. However, the Eppley PSP data plotted versus the cosine of the solar zenith angle shows a looping pattern. The PSP values are too high in the morning, but later in the day after the frost on the Eppley PSP had dissipated, the two radiometers show better agreement. Clearly, 
Storm Peak Lab Radiation 20101125
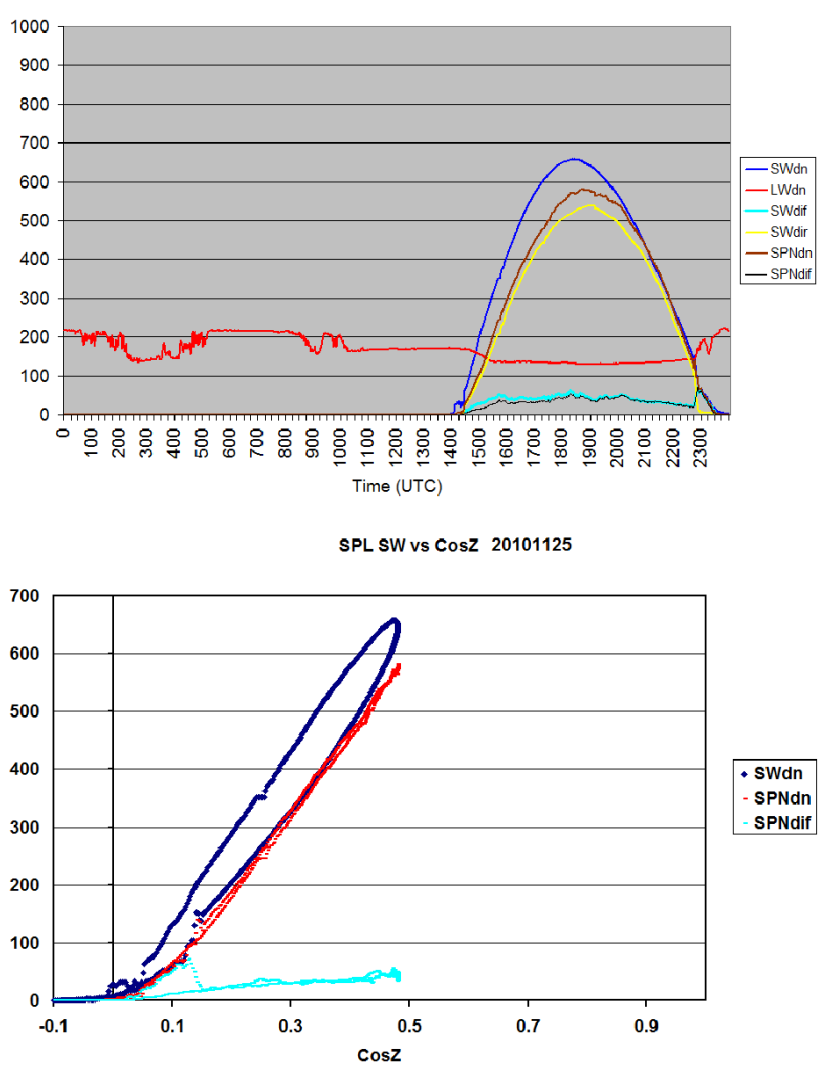

Fig. 8. Top panel: Comparison of SW by Eppley PSP and SNP-1 measurements of global SW at Storm Peak Laboratory on 25 November 2010. Blue curve shows enhanced PSP-measured global SW during the first half of the day due to the frost on the dome as compared to the brown curve representing the SPN-1 total SW. Other data shown are downwelling LW (red), direct SW on a horizontal surface (yellow), PSP-measured diffuse SW (cyan) and SPN1-measured diffuse SW (black). Bottom panel: Eppley PSP global SW (dark blue line) and SNP-1 global SW (red line) versus the cosine of the solar zenith angle. Light blue curve is the SPN-1 measured diffuse SW.

even though it is less accurate under normal conditions, the frost and rime-free SPN-1 produced the more accurate data on that day than the class- 1 instrument. The next task is to develop algorithms and procedures for choosing the "best" measurements at any given time to produce a useful "best estimate" for users.

The versatility afforded by new instruments such as the SPN-1, with its internal heating and ability to produce reasonable total and diffuse SW measurements, opens up a new possible deployment scenario for conditions where fielding a solar tracker is problematic or not feasible and/or riming poses a substantial problem. In those cases, the optimal system might consist of a standard SPN-1 for SW component measurements, a no-shading-pattern SPN-1 for the global SW horizontal measurements, and a heated ventilated PIR

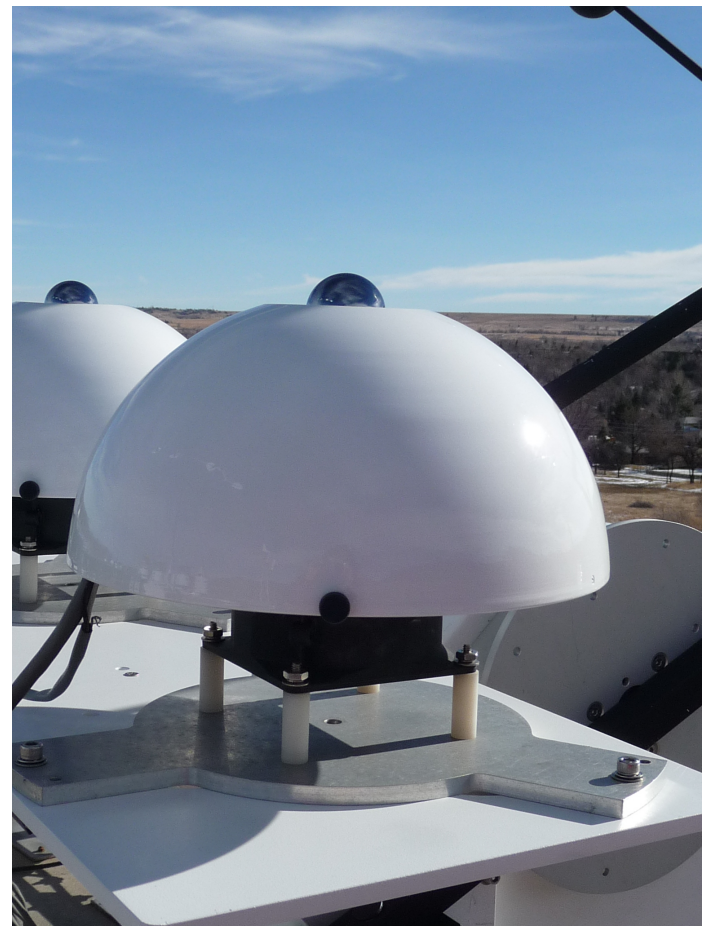

Fig. 9. An Eppley pyrgeometer (PIR) in an arctic-rated ventilator.

(or CG-4) for the LW measurements. It must be noted that the no-shading-pattern SPN-1 is a new concept that has yet to be tested for riming resistance under harsh arctic conditions. Since, by design, conduction through the metal shading pattern helps to more evenly distribute the heating under the SPN-1 dome, some decrease in the ability to resist frost and riming in the no-shading-pattern SPN-1 may manifest itself. Nevertheless, the heating design obviously has an advantage over no heating for arctic conditions.

Another possible area of improvement for cold-climate radiation measurements is proper and adequate heated ventilation (McArthur, 2004; Lanconelli et al., 2011). Figure 9 shows an example of an arctic-rated ventilator: the Physikalisch-Meteorologisches Observatorium Davos (PMOD) model VHS with a heated coil under the sun shield and steep sides to enhance its snow shedding ability. Proper arctic-rated ventilation systems (e.g. PMOD or Kipp and Zonen) that reduce riming or the build-up of snow are a necessity in the arctic environment for non-heated instruments. This is especially the case for the LW sensors because the downwelling IR signal resulting from partial to complete dome ice obscuration may be indistinguishable from legitimate signals from low level clouds (E. Dutton, personal communication, 2010). However, the amount of heating and how the heaters are placed in the ventilator can also contribute to increased IR loss errors in the pyranometer measurements, thus care must be taken in applying this type of ice mitigation strategy. 


\section{Conclusions}

Making surface radiation measurements in the harsh arctic environment is a challenging endeavor. Here we have tried to address problems facing the BSRN working group "Cold Climate Issues" by identifying issues and providing possible solutions. However more work needs to be done. The ultimate goal is to prevent tracker aiming errors and contamination of the measurements by frost, ice, snow, and rime at all times. This might be achieved by a carefully designed solar tracker operation strategy, having adequate and welldesigned radiometer heating and ventilation, and the use of redundant multi-variable radiometers for better data quality control, and the addition of new heated multi-variable radiometers with no moving parts that measure solar components, albeit with lesser accuracy, to cover periods when the solar tracker is inoperable or during periods of severe riming. Perhaps, the incorporation of new instrument types may be required. Establishing viable data quality control, strict dome cleaning schedules, homogenization of the data, and consistent calibration procedures are also necessary for the success of the radiation measurements in the Arctic. Some of these practices will also benefit BSRN stations worldwide, regardless of their location. Last, the addition of upwelling irradiance measurements at stations where they do not exist, and surface latent, sensible, and ground heat flux measurements to arctic stations would lead to a better understanding of how residual energy at the surface is utilized. These valuable additions, in turn, would give modelers of arctic surface processes the information they need to improve their models and ultimately lead to better understanding and forecasts.

Acknowledgements. The authors thank Dutton, E., and Michalsky, J. (NOAA/GMD) and McArthur, L. J. B. for their expertise, support and encouragement. We salute all the hard work by CANDAC and Environment Canada operators in Eureka. This work was supported by the NOAA SEARCH program and the Office of Biological and Environmental Research (OBER) of the US Department of Energy (DOE) as part of the Atmospheric System Research (ASR) Program.

Edited by: S. Slijkhuis

\section{References}

Curry, J. A., Hobbs, P. V., King, M. D., Randall, D. A., Minnis, P., Isaac, G. A., Pinto, J. O., Uttal, T., Bucholtz, A., Cripe, D. G., Gerber, H., Fairall, C. W., Garrett, T. J., Hudson, J., Intrieri, J., Jakob, M. C., Jensen, T., Lawson, P., Marcotte, D., Nguyen, L., Pilewskie, P., Rangno, A., Rogers, D. C., Strawbridge, K. B., Valero, F. P. J., Williams, A. G., and Wylie, D.: FIRE Arctic Clouds Experiment, B. Am. Meteorol. Soc., 81, 5-29, 2000.

Darby, S. L., Dlugokencky, E., Schnell, R., Uttal, T., Vasel, B., Burkhart, J., Drummond, J., Fogal, P., Makshtas, A., Matrosova, L., Albee, R., and Zimov, S.: International Arctic Systems For Observing The ATtmosphere (IASOA): An
Overview Of International Polar Year Activities, Am. Meteorol. Soc., 10th Conference on Polar Meteorology and Oceanography, Madison, Wisconsin, extended abstract, iasoa.org/iasoa/ images/stories/darby_ams_iasoa_extended_abstract.pdf (last access: 17 February 2012), 19 May 2009.

Dines, W. H.: The heat balance of the atmosphere, Q. J. Roy. Meteorol. Soc., 43, 151-158, 1917.

Dong, X., Xi, B., Crosby, K., Long, C. N., Stone, R. S., and Shupe, M. D.: A 10 year climatology of Arctic cloud fraction and radiative forcing at Barrow, Alaska, J. Geophys. Res., 115, 1-14, 2010.

Dutton, E. G.: Tenth session of the baseline surface radiation network (BSRN), WCRP informal report, 2008.

Dutton, E. G., Michalsky, J. J., Stoffel, T., Forgan, B. W., Hickey, J., Nelson, D. W., Alberta, T. L., and Reda, I.: Measurement of broadband diffuse solar irradiance using current commercial instrumentation with a correction for thermal offset errors, J. Atmos. Ocean Tech., 18, 297-314, 2001.

Dutton, E. G., Nelson, D. W., Stone, R. S., Longenecker, D., Carbaugh, G., Harris, J. M., and Wendell, J., Decadal variations in surface solar irradiance as observed in a globally remote network, J. Geophys. Res., 111, D19101, doi:10.1029/2005JD006901, 2006.

Gulbrandsen, A.: On the use of pyranometers in the study of spectral solar radiation and atmospheric aerosols, J. Appl. Meteorol., 17, 899-904, 1978.

Horst, T.: SHEBA FLUX-PAM Project Report, www.eol.ucar.edu/ isf/projects/sheba/rad.isff.html (last access: 17 January 2012), 2003.

Hunt, G. E., Kandel, R., and Mecherikunnel, A. T.: A history of pre satellite investigations of the earth's radiation budget, Rev. Geophys., 24, 351-356, 1986.

IPCC, 2007: Summary for Policymakers, in: Climate Change 2007: The Physical Science Basis, Contribution of Working Group I to the Fourth Assessment Report of the Intergovernmental Panel on Climate Change, edited by: Solomon, S., Qin, D., Manning, M., Chen, Z., Marquis, M., Averyt, K. B., Tignor, M., and Miller, H. L., Cambridge University Press, Cambridge, UK and New York, NY, USA, 2007.

Kay, J. E., L'Ecuyer, T., Gettelman, A., Stephens, G., and O’Dell, C.: The contribution of cloud and radiation anomalies to the 2007 Arctic sea ice extent minimum, Geophys. Res. Lett., 35, L08503, doi:10.1029/2008GL033451, 2008.

Kiehl, J. T. and Trenberth, K. E.: Earth's Annual Global Mean Energy Budget, B. Am. Meteorol. Soc., 78, 197-208, 1997.

Lanconelli, C., Busetto, M., Dutton, E. G., Ko“nig-Langlo, G., Maturilli, M., Sieger, R., Vitale, V., and Yamanouchi, T.: Polar baseline surface radiation measurements during the International Polar Year 2007-2009, Earth Syst. Sci. Data, 3, 1-8, 2011, http://www.earth-syst-sci-data.net/3/1/2011/.

Le Treut, H., Somerville, R., Cubasch, U., Ding, Y., Mauritzen, C., Mokssit, A., Peterson, T., and Prather, M.: Historical Overview of Climate Change, edited by: Solomon, S., Qin, D., Manning, M., Chen, Z., Marquis, M., Averyt, K. B., Tignor, M., and Miller, H. L., Cambridge University Press, Cambridge, UK and New York, NY, USA, 2007.

Long, C. N. and Shi, Y.: The QCRad Value Added Product: Surface Radiation Measurement Quality Control Testing, Including Climatologically Configurable Limits, 
Atmospheric Radiation Measurement Program (ARM) Technical Report, ARM/Pacific Northwest National Laboratory, TR074,, technical report, www.arm.gov/publications/tech_reports/ doe-sc-arm-tr-074.pdf, last access: 20 January 2012, 69 pp., 2006.

Long, C. N. and Shi, Y.: An Automated Quality Assessment and Control Algorithm for Surface Radiation Measurements, Open Atmos. Sci. J., 2, 23-37, doi:10.2174/1874282300802010023, 2008.

Mace, J., Matrosov, S. Y., Shupe, M. D., Lawson, P., Hallar, G., Mc-Cubbin, I., Marchand, R., Orr, B., Coulter, R. L., Sedlacek, A., Avallone, L., Long, C. N., Widener, K. B., Bharadwaj, N., and Roeder, L. R.: STORMVEX: The Storm Peak Lab Cloud Property Validation Experiment Science and Operations Plan, ARM Technical Report, DOE/SC-ARM-10-021, ARM/Pacific Northwest National Laboratory, technical report, www.arm.gov/ publications/programdocs/doe-sc-arm-10-021.pdf (last access: 17 January 2012), 2010.

Matsui, N., Long, C., Niebergall, O., McArthur, B., Halliwell, D., Longenecker, D., Augustine, J., and Uttal, T.: Quaility control of the Eureka flux tower radiation measurements by QCRad (progress report), power point presentation, CANDAC workshop, Halifax, Nova Scotia, 2 November 2010.

McArthur, L. J. B.: World Climate Research Programme, Baseline Surface Radiation Network (BSRN) Operations Manual Version 2.1, WMO/TD-No. 879, WCRP/WMO, 2004.

Michalsky, J., Dutton, E., Rubes, M., Nelson, D., Stoffel, T., Wesley, Splitt, M., and DeLuisi, J.: Optimal Measurement of Surface Shortwave Irradiance Using Current Instrumentation, J. Atmos. Ocean. Tech., 16, 55-69, 1999.

Myers, D. R.: Comparison of direct normal irradiance derived from silicon and thermopile global hemispherical radiation detectors, Proc. SPIE, 7773, 77730G, doi:10.1117/12.859732, 2010.

Ohmura, A., Dutton, E. G., Forgan, B., Frohlich, C., Gilgen, H., Hegner, H., Heimo, H., Konig-Langlo, G., McArthur, B., Muller, G., Philipona, R., Pinker, P., Whitlock, C. H., Dehne, K., and Wild, M.: Baseline surface radiation network (BSRN/WCRP): New precision radiometry for climate research, B. Am. Meteorol. Soc., 79, 2115-2136, 1998.

Peterson, C. T. and Vose, R. S.: An Overview of the Global Historical Climatology Network Temperature Database, B. Am. Meteorol. Soc., 78, 2837-2849, 1997.
Philipona, R.: Underestimation of solar global and diffuse radiation measured at Earth's surface, J. Geophys. Res., 107, 4654, doi:10.1029/2002JD002396, 2002.

Randall, D., Curry, J., Battisti, D., Flato, G., Grumbine, R., Hakkinen, S., Martinson, D., Preller, R., Walsh, J., and Weatherly, J.: Status of and outlook for large scale modeling of atmosphericice-ocean interactions in Arctic, B. Am. Meteorol. Soc., 79, 197 219, 1997.

Solomon, A., Morrison, H., Persson, P. O. G., Shupe, M. D., and Bao, J.-W.: Investigation of microphysical parameterizations of snow and ice in Arctic clouds during M-PACE through model observation comparisons, Mon. Weather Rev., 137, 3110-3127, doi:10.1175/2009MWR2688.1, 2009.

Sutter M.: Surface Radiation and Climate at High Latitudes. Homogenization and Analyses of Data from Arctic and Antarctic BSRN Site, Ph. D thesis, Swiss Federal Institute of Technology, 2006.

Trenberth, K. E., Fasullo, J. T., and Kiehl, J.: Earth's global energy budget, B. Am. Meteorol. Soc., 90, 311-323, 2009.

Uttal, T., Makshtas, A., Danilov, A., Schnell, R. C., Reshetnikov, A., Key, J., Knoplev, A., Romanofsky, V., and Laurila, T.: TiksiHydrometeorological Observatory Program of Research First Year Projects and Installations May 30, 2010 Version 1.0., iasoa.org/iasoa/images/stories/travels/tiksi\% 20science\%20plan\%20english.pdf (last access: 17 January 2012), 2010.

Wild, M., Ohmura, A., Gilgen, H., Morcrette, J. J., and Slingo, A.: Deficiencies in GCM-simulated downward longwave radiation inferred from surface observations, in: Current Problems in Atmospheric Radiation, edited by: Smith, W. L. and Timofeyev, Yu. M., A. Deepak Publ., Hampton, VA, 1231-1234, 2001.

Yasunari, T.: GEWEX Asian Monsoon Experiment (GAME), J. Meteorol. Soc. Jpn., 79, 241-605, 2001.

Yin, X., Gleason, B., Vose, R., Compo, G., and Matsui, N.: The International Surface Pressure Databank (ISPD) land component version 2.2, technical report, ftp://ftp.ncdc.noaa.gov/pub/ data/ispd/doc/ISPD22.pdf (last access: 17 January 2012), 2008.

Zhou, Y., Kratz, D. P., Wilber, A. C., Gupta, S. K., and Cess, R. D.: An improved algorithm for retrieving surface downwelling longwave radiation from satellite measurements, J. Geophys. Res., 112, 1-13, 2007. 